\title{
Identifikasi Mantra Suku Sasak di Lombok
}

\author{
Syaiful Bahri*
}

\begin{abstract}
Abstrak
Mantra (uni kodèq, base beciq, kerante kodèq) dalam masyarakat suku Sasak terdiri atas sebelas jenis, yaitu senggègèr, senteguh, sengasihasih, sengadang-adang, senjerit, sembongkem, sengkalis, sembalik/sempalik, sempoter, begik, dan jejampi. Sebelas jenis mantra tersebut diperoleh dengan melakukan wawancara secara langsung kepada orang yang mengetahui, terlepas dari masih atau tidaknya memercayai atau menggunakan mantra tersebut. Dari wawancara tersebut kadang didapatkan data-data tertulis berupa mantra-mantra. Setelah dilakukan pengidentifikasian, struktur mantra dalam masyarakat suku sasak terdiri dari judul, pembuka, pengandaian atau perumpamaan, tujuan, dan penutup.
\end{abstract}

Kata kunci : mantra, jenis, struktur

\section{Pengantar}

Sekarang ini telinga kita sering disuguhi dengan istilah pengobatan herbal ataupun makanan organik. Hal itu sebagai salah satu bentuk reaksi ketika mengetahui bahwa ilmu pengetahuan modern tidak selalu membawa dampak positif bagi kehidupan. Akhir-akhir ini, dalam jangka waktu yang sudah demikian lama, ditemukan dampak-dampak dari hasil ilmu pengetahuan modern yang sangat membahayakan bagi kelangsungan hidup manusia, alam, maupun kehidupan. Sebagai contoh, dalam bidang pertanian, ditemukan dampak dari penggunaan pupuk kimia, yaitu rusaknya kesuburan tanah. Bidang-bidang kehidupan lain pun mengalami hal yang serupa.

Kondisi seperti itu menjadi salah satu alasan bagi manusia, terutama para ilmuan, untuk menggali kembali kearifan lokal (local

\footnotetext{
${ }^{*}$ Sarjana Pendidikan, Pembantu Pimpinan pada Kantor Bahasa Provinsi NTB
} 
wisdom) yang notabene memiliki prinsip "keseimbangan" dalam menjalani segala aktivitas kehidupan (Saharudin, 2009). Hal itu dijadikan dasar bagi pembangunan dan pengembangan masyarakat yang lebih sustainable, lebih lestari dalam berbagai situasi dan kondisi terutama di tengah sistem otonomi daerah seperti sekarang ini. Ahimsa-Putra (2009) menyebutkan alasan yang lebih rinci pemicu penggalian kearifan lokal, yaitu (a) wacana global tentang kegagalan pembangunan di negaranegara dunia ketiga; (b) semakin merosotnya kualitas lingkungan alam; (c) semakin cepatnya kepunahan pengetahuan-pengetahuan yang menjadi basis adaptasi berbagai komunitas lokal; (d) semacam romantisme budaya dan kebutuhan akan adanya jatidiri di tengah arus globalisasi.

Meskipun begitu, Ahimsa-Putra (2009) menjelaskan bahwa upaya tersebut tidak mudah untuk diwujudkan. Salah satu kendala yang sangat penting adalah belum sepenuhnya kearifan lokal tersebut diketahui karena masih "terpendam" dalam budaya dan kehidupan sehari-hari masyarakat sehingga revitalisasi atau pemanfaatan kearifan lokal belum bisa dilakukan. Upaya revitalisasi atau pemanfaatan baru bisa dilakukan apabila kearifan itu telah diketahui dan dipahami dengan baik. Kondisi seperti itu tidak terlepas dari adanya dominasi budaya oral yang masih berkembang hingga sekarang.

Berdasarkan pemikiran tersebut, langkah awal yang harus dilakukan sebelum melakukan pengkajian dan revitalisasi adalah melakukan identifikasi secara mendalam terhadap berbagai kearifan lokal yang tumbuh dan berkembang dalam kehidupan masyarakat. Salah satu kearifan lokal dalam masyarakat suku Sasak di Lombok adalah mantra.

Mantra adalah penghubung antara manusia dengan dunia misteri (Junus, 1976:148). Hal itu menunjukkan bahwa mantra berada pada dua dunia, yaitu dunia manusia dan dunia misteri. Ia merupakan alat dalam 
usaha membujuk dunia misteri-boleh dikatakan dunia gaib-untuk (tidak) melakukan sesuatu terhadap manusia (tertentu), manusia yang mengucapkannya (Junus, 1981:214).

Jika dikaitkan dengan kajian ilmu sastra, mantra merupakan salah satu jenis puisi lama yang notabene tergolong dalam sastra lisan. Sastra lisan merupakan sastra yang disampaikan secara turun-temurun dengan menggunakan media lisan. Dengan begitu, kebertahanan sastra sangat tergantung kepada minat pemilik atau pengguna sastra untuk menurunkan atau menyampaikan kembali kepada keturunannya. Selain itu, penyampaiannya yang menggunakan media lisan memiliki potensi yang sangat besar untuk mengalami pengurangan maupun penambahan dari bentuk awalnya.

Meskipun begitu, berbeda dengan jenis sastra yang lain, ucapanucapan atau kata-kata yang ada dalam mantra memiliki potensi yang sangat besar untuk tetap bertahan atau dengan kata lain perubahannya sangat kecil. Hal itu karena keberadaan mantra dianggap memiliki kekutan magis sehingga kehilangan salah satu kata dikhawatirkan akan menghilangkan kemanjurannya. Keberadaan ucapan maupun kata-kata dalam mantra yang masih mempertahankan atau mendekati keasliannya memiliki kemungkinan yang sangat besar bagi kita untuk menemukan kearifan-kearifan yang dimiliki oleh masyarakat pendukungnya.

Sebagaimana disinggung pada bagian awal, artikel ini mendeskripsian hasil pengidentifikasian mantra masyarakat suku Sasak di Lombok yang menggunakan bahasa Sasak sebagai bahasa daerah dalam kehidupan kesehariannya. Data-data yang diidentifikasi diperoleh dari hasil wawancara langsung dengan orang-orang yang mengetahui tentang keberadaan mantra, terlepas dari masih atau tidaknya (menggunakan atau tidak menggunakan) memercayai mantra tersebut. 
Dari wawancara tersebut juga ditemukan data-data tertulis, yaitu hasil tulisan tangan dari keluarga atau orang-orang terdahulu yang menulis mantra tersebut dengan tujuan untuk dipelajari.

Dalam artikel ini, pendeskripsian akan dibagi menjadi dua. Bagian pertama akan memaparkan jenis-jenis mantra yang ditemukan pada masyarakat suku Sasak di Lombok. Pendeskripsian kedua adalah memaparkan struktur dari mantra tersebut.

\section{Pembahasan}

\subsection{Jenis Mantra}

Masyarakat suku Sasak yang ada di Pulau Lombok memiliki istilah khusus yang memiliki konsep sama dengan istilah mantra dalam sastra lama. Istilah tersebut adalah basâ beciq, uni kodèq, atau keranté kodèq. Meskipun begitu, generasi sekarang lebih mengenal istilah mentere. Shaleh dkk. (1984:15--18) mengemukakan bahwa jenis mantra yang ditemukan dalam masyarakat suku Sasak di Lombok adalah puji, jejampi, senggègèr, dan begik. Pembagian ini berpatokan pada fungsi dari masing-masing mantra tersebut. Senggègèr adalah jenis basâ beciq yang memiliki fungsi sebagai pengubah perasaan orang yang awalnya tidak cinta menjadi cinta. Begik merupakan uni kodèq yang berfungsi untuk membuat orang sakit, seperti perut bengkak, mulut moncong, dan lain-lain. Puji merupakan basâ beciq yang berfungsi untuk menjadikan badan kebal terhadap senjata tajam dan senjata api. Jejampi merupakan basâ beciq yang berfungsi sebagai pengobatan yang biasanya dimiliki oleh para dukun.

Berdasarkan informasi yang diberikan orang yang diwawancarai, terdapat perbedaan makna maupun fungsi dari beberapa istilah yang berkaitan dengan jenis mantra seperti yang dijelaskan di atas. Istilah 
jejampi dikatakan memiliki kesamaan makna dengan istilah basâ beciq, uni kodèq, keranté kodèq, atau mentere secara umum. Ketika seseorang mengatakan, "nie nyeken kadu jejampi" yang bermakna 'Dia sedang menggunakan jejampi yang dimaksud adalah mantra secara umum. Dengan kata lain, mantra tersebut belum mengarah pada jenis mantra tertentu. Penggunaan istilah jejampi untuk mengobati penyakit karena tidak ada istilah khusus yang digunakan untuk menyebut mantra yang memiliki fungsi sebagai pengobatan.

Istilah Puji ditemukan dua pengertian yang berbeda pada informan yang berbeda pula. Pertama, puji dikatakan memiliki kesamaan makna dengan istilah basâ beciq, uni kodèq, keranté kodèq, mentere, atau jejampi secara umum. Kedua, puji sering dilekatkan (kadang disamakan) dengan jenis mantra yang berfungsi untuk menarik hati atau menumbuhkan perasaan senang.

Kedua pengertian tersebut tentunya sangat berbeda dengan istilah puji yang berfungsi membuat tubuh kebal sebagaimana yang ditemukan oleh Sunaryo dkk. Dari data yang saya temukan, mantra yang berfungsi membuat tubuh kebal disebut dengan istilah senteguh.

Dari segi kuantitas, ditemukan jenis mantra yang lebih beragam jika dibandingkan dengan jenis mantra yang ditemukan oleh Shaleh dkk. Meskipun begitu, sama seperti Shaleh dkk., tidak semua jenis tersebut didapatkan karena terdapat jenis mantra tertentu yang penurunannya harus melalui upacara, waktu, dan persembahan khusus. Adanya hubungan kekerabatan secara langsung juga terkadang menjadi salah satu sarat sehingga mantra tersebut tidak bisa diberikan kepada peneliti yang notabene bukan keturunannya.

Berdasarkan informasi yang diperoleh, terdapat beberapa jenis mantra yang digunakan oleh masyarakat suku Sasak di Lombok. 
Pengategorian masing-masing jenis didasarkan pada fungsi mantra tersebut. Berikut ini masing-masing jenis mantra tersebut yang akan dijelaskan satu per satu.

\subsubsection{Senggègèr}

Senggègèr merupakan jenis mantra yang berfungsi mengubah hati orang menjadi gègèr. Kata gègèr yang ada dalam bahasa Sasak memiliki padanan makna dengan girang dalam bahasa Indonesia. Dengan begitu bisa dikatakan bahwa senggègèr dapat mengubah perasaan orang yang tidak mau atau tidak tertarik menjadi mau atau tertarik terhadap orang atau apapun yang diinginkan, misalnya lawan jenis yang awalnya tidak tertarik menjadi tertarik; seorang anak yang awalnya tidak mau disunat menjadi mau disunat; dan lain-lain. Dari pengertian tersebut kita dapat menarik kesimpulan bahwa senggègèr dapat digolongkan menjadi dua, yaitu (1) senggègèr yang berfungsi menarik hati lawan jenis agar mencintai orang yang diniatkan; (2) senggègèr yang berfungsi menarik hati orang lain untuk melakukan sesuatu seperti yang diinginkan oleh pengguna senggègèr. Dari hasil wawancara didapatkan lima mantra senggègèr jenis pertama dan satu senggègèr jenis kedua.

Berikut ini akan ditampilkan masing-masing satu data dari masing-masing jenis tersebut disertai dengan terjemahan berdasarkan kata. Dalam proses penafsiran terdapat kata-kata yang tidak ditemukan maknanya. Kata-kata tersebut ditandai dengan tulisan yang dimiringkan. 
Data senggègèr jenis pertama.

Bismillahirrahmanirrahim

Humbil-humbil bale beta lia

Humbil-humbil bale beta tau

Jibrail antar beta punya asap rokok

Sampai di...

Berkat lailahaillallah Muhammadarrasulullah
'Dengan menyebut nama Allah yang Maha Pengasih lagi Maha Penyayang`

'Humbil-humbil rumah saya lia'

'Humbil-humbil rumah saya orang`

'Jibrail antar saya punya asap rokok'

'Sampai di...(sebut nama orang yang diniatkan)'

'Berkat tiada Tuhan selain Allah dan Muhammad Rasul Allah

Data senggègèr jenis kedua

Bismillahirrahmanirrahim

Gelemperku aku

Gelemperku pusuk dui

Senggègèr...

Berkat lailahaillallah Muhammadarrasulullah
'Dengan menyebut nama Allah yang Maha Pengasih lagi Maha Penyayang

'Gelemperku aku'

'Gelemperku pucuk duri'

'Senggègèr...(sebut yang diinginkan, misalnya agar anak mau disunat)

'Berkat tiada Tuhan selain Allah dan Muhammad Rasul Allah`

Meskipun senggègèr bermakna mantra yang berfungsi menjadikan orang gègèr dalam segala hal yang diinginkan pemakai, tetapi lebih populer dengan makna menarik hati lawan jenis. Ketika kita menyebut istilah senggègèr, sebagian besar masyarakat akan mengarahkan pikirannya pada mantra yang berkaitan dengan upaya pria memikat hati wanita atau sebaliknya. Anggapan seperti itu menjadikan senggègèr yang berfungsi untuk memikat hati lawan jenis lebih banyak dibandingkan senggègèr yang membuat orang tertarik melakukan sesuatu, selain memikat hati lawan jenis.

\subsubsection{Senteguh}

Senteguh adalah jenis mantra yang berfungsi menjadikan tubuh kebal terhadap senjata musuh. Penggunaan senteguh biasanya digunakan ketika berperang atau melakukan perkelahian. 


\section{Data Senteguh}

Bismillahirrahmanirrahim

Allahumma doa perkumpulan mulih Maring roh nyawa berkumpul

Perkumpulan gedong sejati

Banyu keras banyu mandek

Geni keras geni mandek

Dindingku serte Allah

Payungku serte Muhammad

Julu kawanku Jibrail, Mikail, Israfil

Berkat lailahaillallah Muhammadarrasulullah
'Dengan menyebut nama Allah yang Maha Pengasih lagi Maha Penyayang` 'Ya Allah doa perkumpulan mendapat'

'Baik roh nyawa berkumpul'

'Perkumpulan bangunan sejati'

'Air keras air mandek'

'Api keras api mandek'

'Dindingku dengan Allah'

'Payungku dengan (nabi) Muhammad'

'Depan temanku (malaikat) Jibrail,

Mikail, Israfil

'Berkat tiada Tuhan selain Allah dan Muhammad utusan Allah`

\subsubsection{Sengasih-asih}

Sengasih-asih merupakan salah satu jenis uni kodèq yang digunakan dengan tujuan agar orang selalu merasa senang melihat pengguna atau orang yang diniatkan oleh pembaca mantra. Selain itu, sengasih-asih juga memiliki fungsi mengubah perasaan orang yang awalnya benci menjadi senang terhadap kehadiran atau keberadaan pengguna atau orang yang diniatkan. Dengan menggunakan sengasihasih, seseorang akan selalu disenangi oleh orang-orang yang ada di sekitarnya.

\section{Data Sengasih-asih}

Bismillahirrahmanirrahim

Banyuku seperti bulan purnama

Dudukku seperti bintang di langit

Hari menangis dari belakang

Raja seribu raja

Tunduk hatinya .... kepadaku

Berkat lailahaillallah Muhammadarrasulullah
'Dengan menyebut nama Allah yang Maha Pengasih lagi Maha Penyayang

'Airku seperti bulan purnama`

'Dudukku seperti bintang di langit'

'Hari menangis dari belakang'

'Raja seribu raja'

'Tunduk hatinya....(sebut orang yang menjadi tujuan)

'Berkat tiada Tuhan Selain Allah dan Muhammad Rasul Allah` 


\subsubsection{Sengadang-adang}

Sengadang-adang berasal dari kata adang yang bermakna tangkal. Sesuai dengan makna asal katanya, sengadang-adang berfungsi untuk menangkal ilmu yang akan mencelakai kita maupun orang lain. Ilmu tersebut biasanya sengaja dilepas atau dipergunakan oleh orang yang tidak senang.

Sengadang-adang merupakan mantra yang bersifat preventif, yaitu melindungi seseorang sebelum terkena ilmu orang lain yang bertujuan mencelekakan. Karena bersifat preventif, mantra tersebut harus terus digunakan sehingga diharapkan akan menyatu dengan diri pemakai.

\section{Data Sengadang-adang}

Bismillahirrahmanirrahim

Aku asal Adam

Tongkatku Adam

Tubuhku Rasulullah

Jibrail,Mikail,Israfilmemeliharatubuhnyawaku

Malaikat dilambahku

Wali dipagarku

Pusat langit perjagaan awakku

Berkat lailahaillallah Muhammadarrasulullah
'Dengan menyebut nama Allah yang Maha Pengasih lagi Maha Penyayang`

'Saya asal Adam`

'Tongkatku Adam`

'Tubuhku Rasulullah`

(Malaikat) Jibrail, Mikail, Israfil memelihara tubuh (dan) nyawaku` 'Malaikat menjadi pagarku (pagar keliling)'

'Wali menjadi pagarku'

'Pusat langit menjaga tubuhku'

'Berkat tiada Tuhan selain Allah dan Muhammad Rasul Allah`

\subsubsection{Senjerit}

Senjerit merupakan jenis keranté kodèq yang digunakan agar orang atau binatang buas menjadi takut atau tidak berani melihat atau mendekati kita. Pemberian nama senjerit biasanya menggunakan nama sesuatu atau binatang yang biasanya ditakuti, misalnya senjerit macan. Penggunaan nama macan disebabkan merupakan binatang yang menyeramkan dan ditakuti. Dengan begitu diharapkan pengguna senjerit ditakuti seperti orang takut pada macan. 


\section{Data Senjerit Macan}

Bismillahirrahmanirrahim

Geronsongku gerensengku

Suaraku dadi gangsâ

Imam Barong leq dadengku

Macan putiq ngapit aku

Macan galak neng matangku

Runtu-ranti

Bute matanbi

Bute atenbi

Sèkep kekep

Berkat lailahaillallah Muhammadarrasulullah
'Dengan menyebut nama Allah yang Maha Pengasih lagi Maha Penyayang`

'Geronsongku gerensengku'

'Suaraku jadi gangsâ`

'Imam Barong di dadaku'

'Macan putih mengapitku'

'Macan galak ke mataku'

'Runtu- ranti

'Buta matamu’

'Buta hatimu'

'Sembunyikan (ke tempat terdalam)'

'Berkat tiada Tuhan selain Allah dan Muhammad Rasul Allah`

\subsubsection{Sembongkem}

Sembongkem merupakan jenis mantra yang digunakan agar orang yang kita niatkan tidak bisa berbicara atau berkomentar. Jenis mantra ini biasanya digunakan untuk membantu pengguna mantra dalam situasi-situasi terjepit atau terpaksa (tidak ada pilihan lain), misalnya membuat diam penjual makanan ketika dalam situasi terjepit makanannya kita makan tanpa harus membayar. Mantra ini tidak akan manjur ketika digunakan untuk mainan, merugikan orang lain, atau tidak dalam situasi terjepit.

\section{Data Sembongkem}

Bismillahirrahmanirrahim

Sabtu, Ahad

Senin, Selasa

Rabu, kem...kem... kem...

Berkat lailahaillallah Muhammadarrasulullah
'Dengan menyebut nama Allah yang Maha Pengasih lagi Maha Penyayang` 'Sabtu, Ahad`

'Senin, Selasa'

'Rabu, Kem...Kem...Kem...'

'Berkat tiada Tuhan selain Allah dan Muhammad Rasul Allah`

\subsubsection{Sengkalis}

Sengkalis merupakan salah satu jenis mantra yang berfungsi sebagai penangkal agar kita tidak dimangsa oleh binatang atau tidak terkena oleh benda-benda tertentu yang membahayakan. Selain itu, 
sengkalis juga bisa digunakan sebagai penangkal ilmu-ilmu yang dilepaskan orang lain yang bertujuan mencelakakan diri kita. Jenis mantra ini disebut juga dengan istilah éndé. Disebut demikian karena mantra ini memiliki sifat yang sama dengan éndé, yaitu alat yang digunakan sebagai tameng dalam perisaian.

Sengkalis ini memiliki nama sesuai dengan sesuatu yang ingin ditangkal. Dari hasil penelusuran di lapangan ditemukan tiga sengkalis: sengkalis makhluk, sengkalis batu, dan sengkalis besi. Sengkalis makhluk berfungsi sebagai penangkal agar tidak terkena pukulan atau terkaman mahluk hidup, seperti manusia, jin, atau binatang. Sengkalis batu adalah sengkalis yang berfungsi sebagai penangkal agar tidak terkena lemparan batu, sedangkan sengkalis besi berfungsi sebagai penangkal agar tidak terkena senjata tajam atau senjata apapun yang terbuat dari besi.

\section{Data Sengkalis Makhluk}

Bismillahirrahmanirrahim

Aku Kancing Gedong Langit Jite Nabi

Muhammad 3x

Bismillahirrahmanirrahim

Empat gumi, empat langit

Empat segare, empat angin

Setan mare, setan mati

Manusia mare, manusia mati

Singe mare, singe mati

Berkat lailahaillallah

Muhammadarrasulullah
'Dengan menyebut nama Allah yang Maha Pengasih lagi Maha Penyayang` 'Aku kancing gedung langit jite Nabi Muhammad 3x

'Dengan menyebut nama Allah yang Maha Pengasih lagi Maha Penyayang`

'Empat bumi, empat langit'

'Empat laut, empat angit'

'Setan babak belur, setan mati

'Manusia babak belur, manusia mati

'Singa babak belur, singa mati

'Berkat tiada Tuhan selain Allah dan

Muhammad Rasul Allah 
Data Sengkalis Batu

Bismillahirrahmanirrahim

Masmu laying

Aranmu batu

Batu kidal Baitul Mukaddis

Berkat lailahaillallah

Muhammadarrasulullah

\author{
'Dengan menyebut nama Allah yang \\ Maha Pengasih lagi Maha Penyayang' \\ 'Masmu layang' \\ 'Namamu batu' \\ 'Batu kidal Baitul Mukaddis` \\ 'Berkat tiada Tuhan selain Allah dan \\ Muhammad Rasul Allah
}

Data Sengkalis Besi

Bismillahirrahmanirrahim

'Dengan menyebut nama Allah yang Maha

Allahu ahadiyatullah $3 \mathrm{x}$

Pengasih lagi Maha Penyayang'

Allah wahidiyatullah

'Allah Esa hidayah/petunjuk Allah`

'Allah Esa hidayah/petunjuk Allah`

Allah wahdaniyatullah

'Allah Esa hidayah/petunjuk Allah`

Ujud ilmu nur suhud

Jawat nabat hiwani hujudullah

Sipatullah kup nama besi hasrani

'Ada ilmu cahaya suhud

'Biji-bijian tumbuhan hewan keberadaan Allah`

'Sifat Allah kup nama besi hasrani`

Berkat lailahaillallah Muhammadarrasulullah

'Berkat tiada Tuhan selain Allah dan Muhammad Rasul Allah`

\title{
2.1.8 Sempalik/Sembalik
}

Sempalik atau sembalik merupakan mantra yang berfungsi untuk membalikkan atau mengembalikan ilmu yang sudah mengenai diri kita atau orang lain. Mantra ini biasanya digunakan apabila penyakit yang diakibatkan oleh ilmu tersebut tidak bisa diobati. Dengan sembalik/sempalik, penyakit yang ditujukan kepada kita akan kembali kepada pengirimnya sehingga pengirim tersebut merasakan sakit seperti yang kita rasakan. 


\section{Data Sembalik/Sempalik}

Bismillahirrahmanirrahim

Kulhu balik kulhu bolak kebalik

Kebolak rohing noroning rase

Rase noroning roh mapan aku gaduh

Sentulak sempalik

Palik 3x

Aku gaduh kulhu balik

Berkat lailahaillallah Muhammadarrasulullah
'Dengan menyebut nama Allah yang Maha Pengasih lagi Maha Penyayang

'Katakan Dia balik katakan Dia bolak terbalik

'Terbolak rohing menurunkan rasa

'Rasa menurunkan roh mapan aku gaduh

'Pengembali pembalik'

'Balik'

'Aku gaduh katakana Dia balik`

'Berkat tiada Tuhan selain Allah dan Muhammad Rasul Allah`

\subsubsection{Begik}

Begik memiliki padanan dengan istilah tenun, teluh, atau santet dalam bahasa Indonesia. Jenis mantra ini berfungsi membuat sakit bahkan bisa menghilangkan nyawa seseorang, tergantung niat dan kemanjuran begik yang dimiliki. Begik pada daerah tertentu di Pulau Lombok sering juga disebut dengan istilah sokèq. Jenis mantra ini merupakan mantra bermagis hitam yang tergolong berat dan sangat berbahaya sehingga tidak sembarangan orang memilikinya. Berdasarkan pengakuan informan yang diwawancarai dalam penelitian ini, mereka tidak mau mempelajari jenis mantra ini. Selain berbahaya, mempelajari jenis mantra ini membutuhkan pengorbanan yang sangat berat, misalnya membutuhkan salah satu anggota keluarga kita untuk dijadikan tumbal. Oleh karena itu, dalam penelitian ini tidak ditemukan data mantra jenis begik.

\subsubsection{Sempoter}

Sempoter merupakan salah satu jenis mantra yang berfungsi menjebak seseorang yang bermaksud bermaksud jahat agar tidak bisa atau tidak mengetahui jalan pulang ke rumahnya. Orang yang terkena 
sempoter hanya berputar-putar di sekitar tempat mantra tersebut dilepas atau digunakan sampai mantra tersebut dicabut oleh penggunanya. Sebagai contoh pernah terjadi seorang pencuri yang ingin mencuri sapi hanya berputar di sekitar kandang sampai pagi dan diketahui penduduk sambil membawa sapi yang akan dicuri. Jenis mantra ini lebih sering digunakan pada sèlaq/tusèlaq atau dalam masyarakat Bali lebih dikenal dengan istilah lèak. Sama seperti begik, data jenis mantra ini tidak ditemukan dalam penelitian ini.

\subsubsection{Jejampi}

Seperti sudah dijelaskan di atas, pada dasarnya jejampi memiliki pengertian yang sama dengan pengertian mantra secara umum. Meskipun begitu, informan yang lain memaknai jejampi sebagai mantra yang berfungsi sebagai pengobatan. Dalam penelitian ini, istilah tersebut digunakan untuk mantra-mantra yang tidak bisa digolongkan dalam sepuluh jenis mantra di atas. Penyebutan istilah ini biasanya diikuti dengan fungsi dari mantra, misalnya jejampi betaletan bagi mantra yang digunakan untuk menanam; jejampi bejagur untuk mantra yang berfungsi mengeraskan pukulan.

\section{Data Jejampi Betaletan}

Bismillahirrahmanirrahim

Eh, nabi Adam

Yak sodoq talet puntiq

Jari kakenan umat nabi Muhammad

Aden ndeq tekiq tetombet

Daye andang segare daye tesusum

Timuq andang, segare timuq tesusum
'Dengan menyebut nama Allah yang Maha Pengasih lagi Maha Penyayang`

'Hai, Nabi Adam'

'Saya titip menanam pisang

'Jadi makanan umat Nabi

Muhammad

'Biar tidak diganggu'

'Hadap utara, laut utara tesusum

'Hadap timur, laut timur tesusum 
Berkat lailahaillallah Muhammadarrasulullah

'Berkat tiada Tuhan selain Allah dan

Muhammad Rasul Allah`

\section{Data Jejampi Bejagur}

Bismillahirrahmanirrahim

Rente-renti mapan aku

Gaduh Raja Banas

Hadma hangrarasati

Aku gaduh megat male

Duk masnyawe

Berkat lailahaillallah Muhammadarrasulullah
'Dengan menyebut nama Allah yang Maha Pengasih lagi Maha Penyayang

'Rente-renti mapan aku'

'Gaduh Raja Banas`

'Hadma hangrarasati

'Aku gaduh megat male`

'Duk masnyawe'

'Berkat tiada Tuhan selain Allah dan Muhammad Rasul Allah`

\section{Data Jejampi Memperlancar/Memperbanyak ASI}

Bismillahirrahmanirrahim

Kayuq kukun

Kayuq kelaq

Aden kumpul aiq susum

Saq léq timuq sampé bat

Berkat lailahaillallah Muhammadarrasulullah
'Dengan menyebut nama Allah yang Maha Pengasih lagi Maha Penyayang`

'Kayu kukun`

'Kayu untuk memasak'

'Biar kumpul air susumu'

'Yang di timur sampai barat'

'Berkat tiada Tuhan selain Allah dan Muhammad Rasul Allah`

Selain jenis-jenis mantra di atas tentunya masih banyak jenisjenis mantra lain dengan istilah-istilah yang khusus. Perlu pendekatan yang lebih lama guna mendapatkan data-data tersebut. Hal itu disebabkan keberadaan mantra yang masih dianggap sebagai sesuatu yang sakral dan tidak bisa diturunkan kepada orang sembarangan.

\subsection{Struktur Mantra}

Sama seperti mantra-mantra yang dimiliki oleh suku-suku lain, mantra yang digunakan oleh masyarakat tutur bahasa Sasak di Pulau Lombok juga memiliki struktur sistematis. Sebagai karya sastra, masingmasing unsur dalam struktur saling mendukung satu sama lain. Struktur tersebut terdiri dari judul, pembuka, pengandaian atau perumpamaan, tujuan, dan penutup. 


\subsubsection{Judul}

Unsur judul merupakan sebutan atau nama dari mantra yang membedakan antara mantra yang satu dengan mantra yang lain. Dari judul kita bisa mengetahui fungsi, khasiat, atau penggunaan mantra.

Dalam masyarakat tutur bahasa Sasak di Lombok, masing-masing mantra dalam satu jenis memiliki judul untuk membedakannya dengan mantra yang lain. Penamaan ini disesuaikan dengan media yang digunakan maupun sesuatu yang menjadi representasi dari apa yang diinginkan, misalnya senggègèr rokok untuk senggègèr yang menggunakan rokok sebagai media; senggègèr Nabi Yusuf yang menginginkan wujud pengguna senggègèr seperti wujud Nabi Yusuf. Jika tidak memiliki judul khusus, nama jenis dari suatu mantra dijadikan sebagai judul, misalnya sengasih-asih, sengadang-adang, dan lain-lain.

Apabila suatu mantra tidak bisa digolongkan dalam sembilan jenis mantra yang sudah disebutkan di awal maka digunakan judul/sebutan yang bermakna mantra secara umum, yaitu jejampi atau mentere yang diikuti dengan fungsi/kegunaan mantra tersebut, misalnya mentere sakit tian (mantra untuk sakit perut), mentere betaletan (mantra untuk menanam), dan lain-lain.

\subsubsection{Pembuka}

Unsur pembuka dalam mantra-mantra yang ada dalam masyarakat tutur bahasa Sasak di Pulau Lombok adalah ucapan bismillahirrahmanirrahim. Ucapan ini digunakan hampir di seluruh mantra, kecuali jenis mantra yang bertujuan mencelakakan orang lain, begik atau Sokèq.

Bismillahirrahmanirrahim merupakan kalimat pembuka bahasa Arab yang biasanya diucapkan oleh umat Islam ketika memulai atau 
mengawali setiap kegiatan. Hal ini menunjukkan bahwa mantra-mantra suku Sasak mendapat pengaruh Islam yang notabene manjadi agama mayoritas di Pulau Lombok. Kalimat dalam pembuka ini sudah mendarah daging sehingga tidak bisa diketahui/dilacak ucapan pembuka yang digunakan sebelum pengaruh Islam masuk dalam mantra suku Sasak.

\subsubsection{Pengandaian atau Perumpamaan}

Unsur pengandaian atau perumpamaan merupakan unsur yang berisi analogi, sugesti, penggambaran, atau suasana yang diinginkan dari penggunaan mantra tersebut. Dalam unsur ini terdapat gambaran suasana, seperti suasana alam yang seakan-akan menjadi representasi "gambaran rupa" yang dinginkan oleh pemakai mantra. Hal ini misalnya dapat kita lihat pada jenis mantra senggègèr maupun sengasih-asih yang menggunakan kata bulan purnama, bintang, banyu, dan lain-lain yang dianggap dan diharapkan menjadi representasi pengguna mantra.

\footnotetext{
Banyu suci badanku sampurne `Air suci badanku sempurna`

Banyuku seperti bulan purnama 'Airku seperti bulan purnama`

Dudukku seperti bintang di langit `Dudukku seperti bintang di langit
}

Selain penyebutan suasana alam, disebutkan pula nama atau tokoh sebagai representasi ideal yang diharapkan menjadi gambaran diri penggguna mantra. Penyebutan nama atau tokoh juga menjadi reperentasi dari fisik atau rupa yang diinginkan dan bisa juga sebagai pelindung yang akan terus menjaga pengguna mantra. Nama-nama yang biasa disebut 
adalah nabi dan malaikat, seperti Nabi Adam, Rasulullah, Malaikat Malik, Malaikat Israfil dan lain-lain.

Tongkatku Adam `Tongkatku Adam`

Tubuhku Rasulullah `Tubuhku Rasulullah`

Julu kawanku Jibrail, Mikail, Israfil 'Depan kawanku Jibrail, Mikail, Israfil

Jenis mantra tertentu menyebutkan nama binatang yang menjadi representasi dari harapan yang diinginkan terhadap penggunaan mantra. Dari susunan mantra dapat diketahui bahwa penyebutan nama binatang bertujuan agar pengguna mantra ditakuti seperti orang menakuti binatang yang disebutkan. Selain itu, penyebutan nama binatang juga sebagai bentuk penghindaran terhadap binatang yang disebutkan.

Macan putiq ngapit aku `Macan putih mengapitku`

Macan galak neng matangku `Macan buas di mataku`

\subsubsection{Tujuan}

Bagian tujuan merupakan bagian yang menyebutkan harapan yang diinginkan dari penggunaan mantra. Harapan tersebut disampaikan secara langsung maupun tidak langsung. Penyebutan harapan secara langsung biasanya menggunakan kata-kata atau kalimat yang mengandung makna eksplisit, misalnya "... Jibrail antar beta punya rokok" '...Jibrail antar rokok saya'. Kalimat tersebut merupakan salah satu mantra jenis senggègèr yang dilepaskan melalui asap rokok. Dari kalimat tersebut tergambar secara langsung tujuan/maksud dari penggunaan mantra, yaitu mengantarkan (asap) rokok yang sudah dimantrai. 
Berbeda dengan harapan/tujuan yang disampaikan secara langsung, harapan secara tidak langsung menggunakan kata-kata atau kalimat yang implisit. Harapan yang disampaikan secara tidak langsung biasanya menyabutkan judul atau nama mantra yang digunakan. Nama mantra yang disebutkan biasanya mantra-mantra yang sangat populer, yaitu mantra yang sudah diketahui orang banyak, seperti "Gaduh sengasih-asih senggègèr basong” 'Gaduh sengasih-asih senggègèr anjing`. Kalimat tersebut tidak menggambarkan secara langsung maksud mantra, tetapi hanya disebutkan nama dari mantra tersebut.

\subsubsection{Penutup}

Bagian yang terakhir adalah penutup. Jika bagian pembukaan menggunakan bahasa Arab, yaitu ucapan yang digunakan oleh umat Islam, bagian penutup pun demikian. Pada bagian ini mengatakan, berkat lailahaillallah muhammadarrasulullah. Adanya ucapan ini secara tidak langsung menunjukkan pengakuan bahwa segala sesuatu berpulang kepada Sang Pencipta, manusia hanya bisa berusaha.

\section{Penutup}

\subsection{Simpulan}

Masyarakat suku Sasak sebagai suku mayoritas di Pulau Lombok memiliki istilah khusus yang memiliki makna yang sama dengan mantra, yaitu basâ beciq, uni kodèq, atau keranté kodèq. Akan tetapi, generasi sekarang lebih sering menggunakan istilah mentere dibandingkan dengan ketiga istilah di atas.

Mantra dalam masyarakat suku Sasak dibagi menjadi sebelas jenis. Penggolongan ke dalam jenis-jenis tersebut dilihat berdasarkan fungsi atau kegunaan masing-masing mantra tersebut. Adapun jenis-jenis 
mantra tersebut yaitu (1) senggègèr, (2) senteguh, (3) sengasih-asih, (4) sengadang-adang, (5) senjerit, (6) sembongkem, (7) sengkalis, (8) sembalik/sempalik, (9) sempoter, (10) begik, dan (11) jejampi. Dilihat dari strukturnya, mantra terdiri dari (1) judul, (2) pembuka, (3) pengandaian atau perumpamaan, (4) tujuan, dan (5) penutup.

\subsection{Saran}

Pengidentifikasian dan pendeskripsian sastra lisan, khususnya mantra, membutuhkan waktu dan tenaga yang besar. Upaya ini tentunya harus didukung dan dikerjakan dengan penuh konsisten dan berkelanjutan. Pandangan bahwa mantra merupakan sesuatu yang sakral menjadikannnya sangat sulit untuk dikeluarkan. Untuk itu, penulis meyakini masih banyak mantra-mantra yang menjadi kekayaan lokal yang masih terpendam. Meskipun begitu, dengan pendekatan mendalam, kendala itu akan bisa teratasi. Butuh kesabaran dan ketekunan untuk mendapatkannya. Upaya kita bersama untuk menggali dan mendokumentasikan semuanya guna menemukan kearifan-kearifan yang bisa dijadikan bahan pijakan untuk melangkah menghadapi era yang dikatakan global. 


\section{Daftar Pustaka}

Ahimsa-Putra, Heddy Shri. 2009. "Bahasa, Sastra dan Kearifan Lokal di Indonesia" Makalah Seminar Nasional Bahasa dan Sastra dalam Konteks Keindonesiaan II Kantor Bahasa Provinsi NTB.

Junus, Umar. 1976. Perkembangan Puisi Melayu Modern. Kualalumpur: Dewan Bahasa dan Pustaka . 1981. Mitos dan Komunikasi. Jakarta : Sinar Harapan

Saharudin. 2009. "Refleksi Pola Pikir dan Kearifan Lokal Masyarakat Sasak dalam Ranah Pertanian: Sebuah Investigasi Atas Fakta Linguistik" Makalah Seminar Nasional Bahasa dan Sastra dalam Konteks Keindonesiaan II Kantor Bahasa Provinsi NTB.

Saidi, Shaleh dkk. 1984. Sastra Lisan Sasak. Jakarta: Pusat Pembinaan dan Pengembangan Bahasa

Saputra, Heru S.P.. 2007. Memuja Mantra. Yogyakarta: LKiS 